DOI: $10.19177 /$ reen.v13e12020215-244

\title{
DA AGROINDÚSTRIA A MANUFATURA: ESTUDO SOBRE O PERFIL DOS PEQUENOS NEGÓCIOS, SUA ESTRUTURA ORGANIZACIONAL E ELEMENTOS ESTRATÉGICOS
}

\section{FROM AGROINDUSTRY TO MANUFACTURE: STUDY ON THE PROFILE OF SMALL BUSINESSES, ITS ORGANIZATIONAL STRUCTURE AND STRATEGIC ELEMENTS}

\section{DE LA AGROINDUSTRIA A LA FABRICACIÓN: UN ESTUDIO SOBRE EL PERFIL DE LAS PEQUEÑAS EMPRESAS, SU ESTRUCTURA ORGANIZATIVA Y ELEMENTOS ESTRATÉGICOS}

\author{
Elizangela Veloso Saes \\ Doutorado em Gestão da Produção pela Universidade Federal de São Carlos (UFSCar) \\ Professora adjunta na Universidade Federal de Mato Grosso do Sul (UFMS) \\ Endereço: UFMS, Av. Ranulpho Marques Leal, n. 3484, CEP: 79620080. Três Lagoas, MS, Brasil \\ Telefone: (67) 3509-3803 \\ E-mail: elizangela.saes@ufms.br
}

Moacir Godinho Filho

Pós-doutorado em Aplicação de System Dynamics e Factory Physics à Gestão de Sistemas de

Produção na North Carolina State University - USA

Professor associado 2 na UFSCar

Endereço: UFSCar, Via Washington Luiz, Monjolinho, CEP: 13565905. São Carlos, SP, Brasil

Telefone: (16) 33518240

E-mail: moacir@dep.ufscar.br

\section{Nilton Cezar Carraro}

Pós-Doutorando em Engenharia de Produção na UFSCAR, Doutor em Engenharia de Produção, pela UNIMEP - Universidade Metodista de Piracicaba.

Professor Adjunto da Universidade Federal de São Carlos, Campus Lagoa do Sino.

Endereço: Rod. Lauri Simões de Barros km 12 - SP-189, Aracaçu, 18290000 - Buri, SP.

Telefone profissional: (15) 3256-90000

E-mail: nilton.carraro@ufscar.br

Silvio Paula Ribeiro

Doutorado em Ciências Contábeis pela Universidade do Vale do Rio dos Sinos (UNISINOS)

Professor adjunto na Universidade Federal de Mato Grosso do Sul (UFMS)

Endereço: Av. Ranulpho Marques Leal, n. 3484, CEP: 79620080. Três Lagoas, MS, Brasil

Telefone: (67) 3509-3769

E-mail: spribeiro@hotmail.com

\section{Marco Aurélio Batista de Sousa}

Pós-doutorado em Ciências Contábeis pela Universidade Federal de Uberlândia

Professor associado na UFMS

Endereço: Av. Ranulpho Marques Leal, n. 3484, CEP: 79620080. Três Lagoas, MS, Brasil

Telefone: (67) 3509-3768

E-mail:mcbsousa@bol.com.br

Artigo recebido em 10/09/2019. Revisado por pares em 20/11/2019. Reformulado em 21/11/2019. Recomendado para publicação em 01/12/2019. Publicado em 30/04/2020. Avaliado pelo Sistema double blind review.

(C) Copyright 2020 UNISUL-PPGA/Revista Eletrônica de Estratégia \& Negócios. Todos os direitos reservados. Permitida citação parcial, desde que identificada a fonte. Proibida a reprodução total. Revisão gramatical, ortográfica e ABNT de responsabilidade dos autores. 


\section{RESUMO}

Este trabalho teve como objetivo identificar os fatores que influenciam a estratégia de manufatura, a montante e jusante, analisando o nível de alinhamento entre os diferentes funcionários na definição da estratégia de produção em pequenas e médias empresas. Assim, por meio de uma análise descritiva das empresas no Município de São Carlos, estado de São Paulo foi possível identificar que a maioria delas atuam a mais de 10 anos; possuem de 2 a 4 sócios; tem níveis hierárquicos simples; pode-se dizer que são empresas familiares e utilizam-se da estratégia de manufatura em massa. Contrapondo-se ao conhecimento ínfimo de técnicas modernas.

Palavras-chave: Pequenas Empresas; Estratégia de Produção; Perfil Organizacional; Manufatura em massa; Técnicas de gestão.

\section{ABSTRACT}

This work aimed to identify the factors that influence the manufacturing strategy, upstream and downstream, analyzing the level of alignment among the different employees in the definition of production strategy in small and medium enterprises. So through a descriptive analysis of the companies in the Municipality of São Carlos, state of São Paulo, it was possible to identify that most of them operate for more than 10 years; have 2 to 4 members; has simple hierarchical levels; can be said to be family-owned enterprises and use the massmanufacturing strategy. In contrast to the minimal knowledge of modern techniques.

Keywords: Small business; Production Strategy; Organizational Profile; Mass Manufacturing; Management techniques.

\section{RESUMEN}

Este trabajo tuvo como objetivo identificar los factores que influyen en la estrategia de fabricación, con proveedores y clientes, analizando el nivel de alineación entre los diferentes empleados en la definición de la estrategia de producción para pequeñas y medianas empresas. A través de un análisis descriptivo de empresas en el municipio de São Carlos, estado de São Paulo, fue posible identificar que la mayoría de ellas han estado operando por más de 10 años; tienen de 2 a 4 socios; tienen niveles jerárquicos simples; se puede decir que son empresas familiares y utilizan la estrategia de fabricación en masa, opuesto al mínimo conocimiento de las técnicas modernas.

Palabras clave: Pequeñas empresas; Estrategia de producción; Perfil organizacional; Fabricación en massa; Técnicas de gestión. 


\section{INTRODUÇÃO}

No atual ambiente competitivo, são necessários mais estudos a respeito da importância das Pequenas e Médias Empresas - PME, as quais representam uma parcela significativa no número de empresas e da força de trabalho das principais economias emergentes. Para Gupta e Cawthom (1996), Asc e Preston (1997), Brouthers et al. (2015) e Trianni et al. (2016), as PME são a espinha dorsal do setor manufatureiro mundial.

Assim como na indústria, é possível identificar que as pequenas propriedades rurais também estão ganhando uma conotação de empresas seja por conta da redução do tamanho das propriedades, ou mesmo pela personificação jurídica dos produtores rurais, denominados de agroempresários. Fatores esses muitas vezes motivados pela blindagem jurídica das propriedades e pela redução da carga tributária, haja vista que a tributação da pessoa jurídica no agronegócio pode ser menor do que na pessoa física, segundo Loubet (2009), Possamai (2017) e Tamarindo (2017).

Logo, deve-se acrescentar na análise da literatura específica das PME também o agronegócio, principalmente as agroindústrias, destacando que elas apresentam características próprias quando comparadas às grandes (GUPTA; CAWTHON, 1996; GHOBADIAN; GALLEAR, 1997). De acordo com Braguier (1993), a maioria dos pesquisadores considera árduo o estudo das PME, visto a heterogeneidade que existe entre essas empresas e ao conjunto de características inerentes que as distinguem das empresas de grande porte, afirmando que o reconhecimento dessa heterogeneidade e das características inerentes das PME são premissas incondicionais para o sucesso dos processos estratégicos implantados.

Para Moraes e Escrivão Filho (2006), o planejamento estratégico em PME é essencial, uma vez que mitiga a conduta reativa dessas empresas, tratada, por vezes, como característica intrínseca. Completam afirmando que o planejamento permite reafirmar o curso das ações tidas como corretas ou identificar as áreas ou questões que requerem ajustes finos ou, ainda, a necessidade de ações futuras.

Em relação à propriedade agrícola, Foguesato et al. (2018) chegaram a essa mesma constatação ao executarem uma pesquisa ação no Município de Ajuricaba-RS, na qual foi 
possível provar que o planejamento estratégico agregou melhores resultados a curto e a médio prazo.

Diante desse contexto, o objetivo desta pesquisa é identificar os fatores que influenciam em maior ou menor grau de consenso da estratégia de manufatura, a montante e a jusante (antes, dentro e depois da porteira), analisando o nível de alinhamento entre os diferentes funcionários envolvidos na definição de uma estratégia de produção em pequenas empresas que operam em uma economia emergente. Para tanto, utilizou-se uma análise exploratória e a amostragem representatitativa de vários segmentos econômicos. Justifica-se esse trabalho pela necessidade de ter um cenário atualizado para esse porte de empresa, bem como a utilização de um modelo de cruzamento de dados inovadores.

Logo, o presente trabalho é estruturado da seguinte forma: no início ocorre a introdução do tema, na seção 2 é apresentado um breve referencial teórico sobre PME e Estratégia de Produção, na seção 3 é apresentado a abordagem metodológica. Na seção 4 encontram-se os resultados e discussões e, por fim, na última seção são apresentadas as conclusões, contribuições e propostas para trabalhos futuros.

\section{REFERENCIAL TEÓRICO}

\subsection{PME E SUAS CARACTERÍSTICAS}

As PME não são miniaturas das grandes empresas (WELSH; WHITE, 1981). A literatura específica em PME estabelece que essas empresas são marcadas por um conjunto de características inerentes que as distinguem das grandes (GUPTA; CAWTHON, 1996; GHOBADIAN; GALLEAR, 1997; ALVES FILHO et al., 2010).

Callado e Callado (1999) mencionam que elementos de tomada de decisão por grandes empresas como a contabilidade gerencial e a contabilidade de custos são pouco difundidos em empresas de pequeno porte, inclusive naquelas envolvidas com o agronegócio. Dessa forma, muitas características desse setor carecem de estudos, sobremaneira a tomada de decisão quanto à formação de preços.

De acordo com Leone (1999), o entendimento dessas características permite que os dirigentes das PME administrem seus negócios da forma mais eficaz possível, em um 
ambiente econômico de constante evolução. Moraes e Escrivão Filho (2006) completam essa ideia afirmando que as dificuldades organizacionais enfrentadas pelas PME estão, por vezes, enraizadas em suas próprias especificidades.

Para facilitar a ordenação e o entendimento, as características mais comumente tratadas pela literatura pesquisada são agrupadas por meio de três perspectivas: ambiente, organizacional e gerencial (LEONE, 1999).

Quanto à perspectiva do ambiente, pode-se afirmar que ele é composto por um conjunto de elementos que se localizam além da fronteira interna da empresa, tendo a capacidade de afetá-la em aspectos de crescimento e sobrevivência (LEONE, 1999).

As PME, quando comparadas as grandes, são mais vulneráveis aos efeitos do ambiente, em geral, apresentam menor controle sobre seu ambiente externo. Solomon (1986) observa que as PME exercem pouco poder de barganha nas relações comerciais com fornecedores e clientes de grande porte.

Assim, a sobrevivência dessas empresas depende da maneira em que são estabelecidas suas interações com os clientes, fornecedores, competidores, órgão reguladores e os recursos que dispõem (LEONE, 1999; CURRAN, 2006).

Pensando nessa primeira perspectiva Gomes Rodrigues et al. (2016) aplicaram a Matriz Estratégica do Agronegócio (MEA) como forma de estabelecer o relacionamento da indústria de lacticínios com seus stakeholders, chegando a evidencia que as relações a montante, ou seja, antes da porteira, são o elo mais frágil, confirmando os achados de Leone (1999) e de Curran (2006).

Quanto a perspectiva organizacional, diante das leituras precedidas, destaca-se que a PME aponta para uma estrutura de tomada de decisão mais centralizada do que as grandes (ALMEIDA, 1994; LEONE, 1999). Observou-se ainda que as mesmas possuem uma estrutura organizacional simples, necessitando de uma quantidade menor de unidades ou funções administrativas, não apresentam condições de manter uma estrutura administrativa sofisticada e que os canais de comunicação são simples e informais, sendo estabelecido na 
maioria das vezes face-to-face (DRUCKER, 1992; GHOBADIAN; GALLEAR, 1997; LEONE, 1999; MORAES; ESCRIVÃO FILHO, 2006; CURRAN, 2006; ALVES FILHO et al., 2010).

Desse modo, identifica-se nas PME um baixo nível de maturidade organizacional em que os processos de planejamento, avaliação e controle são, geralmente, pouco formalizados (CHER, 1991; GHOBADIAN; GALLEAR, 1997; LEONE, 1999; MORAES; ESCRIVÃO FILHO, 2006; ALVES FILHO et al., 2010).

De acordo com Moraes e Escrivão Filho (2006, p. 6), tais características conduzem a um comportamento reativo às necessidades do ambiente e a reação, ou ainda, a ação tomada varia de acordo com o porte da empresa, pois em razão do tamanho há variações na estrutura, na organização e formalização dos processos: "quanto menor o tamanho da empresa, menos estruturada em termos de níveis hierárquicos e menor a formalização dos seus fluxos de informação".

Além dessas características, destaca-se que a ausência da formalização dos processos e a prevalência de relações de trabalho soltas e informais, as quais tornam as PME propensas a adotar estruturas organizacionais orgânicas (GHOBADIAN; GALLEAR, 1997). O processo estratégico é tratado no curto prazo, utilizando mais o planejamento operacional do que o planejamento estratégico.

Lopes e Kniess (2015) confirmam as declarações anteriores quanto à estrutura organizacional ao analisarem os fatores que influenciaram a adoção do balanced scorecard (BSC) em uma cooperativa agroindustrial, tendo como um dos principais complicadores o baixo nível de funcionários no setor administrativo e também a sua baixa qualificação.

Quanto à perspectiva gerencial, a maneira de ver, sentir, agir e reagir do estrategista é construída a partir do seu conhecimento, de suas suposições sobre eventos futuros e da identificação e análise que faz de alternativas e de suas respectivas consequências. As decisões gerenciais são conduzidas conforme as preferências e valores de seus gerentes.

De acordo com Alves Filho et al. (2010), as características do dirigente-estrategista (idade, atividades desenvolvidas, experiências, nível educacional e socioeconômico, entre outras) influenciam no desenvolvimento da estratégia e no desempenho da organização. 
(DRUCKER, 1992; GHOBADIAN; GALLEAR, 1997; LEONE, 1999; ALVES FILHO et al., 2010; LOPES; KNIESS, 2015). Esse indivíduo, representado pela função de empreendedor ou proprietário-dirigente, conduz, em muitos casos, com o futuro da empresa com base nos planos, expectativas e necessidades próprias ou de sua família (DRUCKER, 1992; ALVES FILHO et al., 2010).

Portanto, os desejos, anseios, complexos e anseios do proprietário-dirigente são transferidos para o negócio, de modo que nas PME existe pouca diferença entre a pessoa física e jurídica, entre o dirigente e o proprietário que mesmo nas empresas de sociedade anônima, colocam seu patrimônio pessoal a serviço da empresa (CHER, 1991; LEONE, 1999; LOUBET, 2009; TAMARINDO, 2017).

Nesse contexto, tem-se a centralização das decisões por parte dos proprietáriosdirigentes e um vínculo entre a vida pessoal e a vida da empresa, o que conduz à pessoalidade das PME que, por vezes, é acentuada pela presença de parentes em cargos administrativos que, muitas vezes, não tem conhecimento aprofundado nas técnicas de gestão (ALMEIDA, 1994; GONÇALVES; KOPROWISKI, 1995; MORAES; ESCRIVÃO FILHO, 2006).

Desse modo, tem-se que o perfil do proprietário-dirigente é mais o de um estrategista que corre riscos, do que o de um administrador-gestionário que aplica uma estratégia para reduzir os riscos. Leone (1999) observa que a experiência prática fornece a principal contribuição para a formação dos dirigentes, sendo tratado como o "aprender fazendo".

Para Moraes e Escrivão Filho (2006), os dirigentes dão muito valor ao conhecimento baseado na experiência, obtida por uma vivência dentro da empresa. Dessa forma, os dirigentes acreditam que esse conhecimento é suficiente para tomar as decisões, dispensando o emprego de técnicas e instrumentos de gestão, tornando o processo de tomada de decisão, na grande maioria dos casos, intuitivo.

Soma-se ao perfil dos dirigentes o comportamento, fundamentalmente paternalista e, por vezes, egocêntrico que cria a necessidade de uma estreita colaboração entre o dirigente e seus os colaboradores (CHER, 1991; GHOBADIAN; GALLEAR, 1997; LEONE, 1999; CURRAN, 2006). 
Por fim, acrescenta-se a esse perfil o desejo por responsabilidade e independência, a autoconfiança, a necessidade por poder, a criatividade e a busca por inovação que movem grande parte dos proprietários-dirigentes das PME.

\subsection{PROCESSO ESTRATÉGICO EM PME}

Em um contexto geral, a formulação e a implantação das estratégias devem fundamentar em propósitos coerentes com as necessidades, características e desafios das organizações, abrangendo uma série de fatores próprios e ou não das empresas. No que se refere ao estudo específico sobre planejamento estratégico em PME, Bracker e Pearson (1986) propõem um sistema de classificação baseado em quatro categorias:

a) Informal: não existe um plano escrito, isto é, as ações e decisões estão na mente do estrategista que é representado pelo proprietário-dirigente. Assim, há a ausência de um processo de planejamento, o que conduz às ações estratégicas emergentes e intuitivas;

b) Pouco sofisticado: existe um plano escrito que apresenta alguns objetivos específicos voltados, exclusivamente, a área de produção;

c) Moderadamente sofisticado: o processo de planejamento é responsável pela definição dos objetivos aplicáveis às diversas áreas, considerando os fatores externos que influenciam as decisões importantes da empresa. O horizonte de planejamento é até um ano;

d) Sofisticado: nessa última categoria, além da elaboração do plano escrito que identifica fatores externos e abrange toda a empresa, são realizados procedimentos para acompanhar a realização do planejado, sendo sistematicamente avaliado.

Com base nessa classificação, é possível estabelecer que toda a empresa possui uma estratégia, tenha sido ela formulada e implantada a partir de um plano formalizado e previamente deliberado ou emergida a partir de uma sequência de ações desenvolvidas ao longo de um período de tempo (ALVES FILHO et al., 2010).

Vários autores corroboram que o processo de planejamento estratégico em PME é informal, ou seja, intuitivo ou inexistente (LEONE, 1999; CURRAN, 2006; ALVES FILHO et al., 2010). Logo, as atividades de planejamento estratégico em PME, geralmente, ocorrem na 
mente do proprietário, de forma pouco estruturada, não sendo formalizado e sistematicamente comunicada, apresentando um caráter predominantemente emergente (CHER, 1991; GHOBADIAN; GALLEAR, 1997; LEONE, 1999; ALVES FILHO et al., 2010).

De acordo com Moraes e Escrivão Filho (2006), esse caráter emergente baseia-se em flexibilidade, oportunismo, experiências prévias, aprendizado e intuição. Assim, o planejamento estratégico em PME sofre variações em relação às variações do meio em que a organização está inserida, criando um ciclo de ações emergenciais.

Esse ciclo, por sua vez, é alimentado por outro conjunto de características das PME: falta de mão-de-obra especializada; dificuldades na formulação de resposta estratégica, resultante da vulnerabilidade do ambiente externo e atuações reativas face as transformações ambientais (ARAGON-SÁNCHEZ; SÁNCHEZ-MARÍN, 2005 apud ALVES FILHO et al., 2010). Diante do exposto, as ações emergenciais consomem a atenção que poderia ser dada ao processo estratégico (MORAES; ESCRIVÃO FILHO, 2006).

Nesse contexto, a formalização e a sistematização dos processos, rotinas e atividades de planejamentos podem influenciar na quebra deste ciclo, atuando no sucesso estratégico. Esse fato está apoiado nos estudos de Cher (1991), o qual estabelece que o planejamento permite reafirmar o curso de ações tidas como corretas ou identificar as áreas ou questões que requerem ajustes finos ou, ainda, identificar as ações corretivas necessárias. O mesmo raciocínio é desenvolvido por Porter (1989) que destaca, quanto menor é a empresa, mais importante é a formalização da estratégia. Uma vez que as empresas menores, ao contrário das grandes, são mais sensíveis às variações do mercado e, por isso, precisam perceber o ambiente com maior clareza e reagir com maior rapidez. A Fundação Nacional da Qualidade (FNQ, 2008) também pontua essa ação na implantação dos modelos de gestão.

Para Cher (1991), o planejamento estratégico em PME é necessário, uma vez que permite aos gestores assumirem o controle sobre seus negócios, favorecendo que as práticas de negócios sejam conduzidas de forma proativa, ao invés de agir reativamente as situações e problemas do negócio.

Por fim, destaca-se que a intuição e a informalidade promovem uma distinção menor entre as atividades de planejamento e implantação, o que dificulta o acompanhamento de 
uma estratégia (ALVES FILHO et al., 2010), e motiva a busca pela formalização do processo de planejamento em PME.

\subsection{ELEMENTOS DA ESTRATÉGIA DE PRODUÇÃO}

Sendo a formalização do planejamento estratégico um importante passo para o sucesso das empresas sejam elas, grandes ou pequenas, observa-se a necessidade do entendimento dos elementos centrais que constituem as estratégias (SKINNER, 1969; WHEELRIGHT, 1978).

Desse modo, tendo como foco a estratégia de produção, destaca-se que as escolhas que envolvem essa estratégia se tornam mais claras à medida que a mesma é analisada por meio de dois elementos centrais: conteúdo estratégico e processo estratégico (WHEELWRIGHT, 1984; HAYES et al., 2008; SLACK; LEWIS, 2011).

A diferença consensual dos dois elementos estabelece que o conteúdo refere-se a um grupo de decisões que é tomada no domínio da função produção, enquanto que o processo estabelece o modo como essas estratégias são formuladas. Diante do objetivo da pesquisa, serão exploradas questões relacionadas ao conteúdo estratégico.

O objetivo central do conteúdo estratégico é o de estabelecer quais prioridades competitivas são relevantes às empresas e quais políticas devem ser estabelecidas às diferentes áreas de decisão da produção.

De acordo com a literatura pesquisada, estabelece-se que os principais elementos que constituem o conteúdo estratégico podem ser capturados por meio de dois pontos chaves: prioridades competitivas e áreas de decisão (WHEELWRIGHT, 1984; SLACK; LEWIS, 2011).

Corroborando com essas afirmações, o estudo de Da Silva e Alves (2018) analisou a organização interna e a diversidade da produção na agroindústria do dendê, no Nordeste Paraense, chegando à conclusão que muitas vezes o pequeno empresário abre mão de alternativas estratégicas e de crescimento em prol de uma garantia estabelecida por um contrato de compra. 
Esses pontos apresentam interações entre si, as quais estabelecem que as prioridades competitivas devam retratar as necessidades da organização, indicando as metas a serem atingidas que, por sua vez, são alcançadas por um padrão de ações relacionadas às áreas de decisão.

Em relação às prioridades competitivas, Zanon et al. (2013) observam que essas são desdobradas no momento em que a organização define sua posição no mercado (estratégia competitiva) e elege certos critérios para alcançá-la e mantê-la. Dessa forma, é possível estabelecer que as prioridades competitivas se referem a um conjunto consistente de critérios em que a função da produção terá para competir no mercado durante e em certo horizonte de tempo. Completam essa informação, afirmando que um conjunto consistente de critérios orientará a função produção na escolha e implantação de programas.

Diante das leituras realizadas, tem-se que as prioridades competitivas comumente tratadas na literatura são: custo, qualidade, desempenho das entregas, flexibilidade e inovação (SKINNER, 1969).

Já quanto nas áreas de decisão, Slack e Lewis (2011) estabelecem que esse elemento estratégico contemplam um conjunto de questões sobre o projeto de produção que envolvem decisões estruturais e uma série de decisões que influenciam a força e o trabalho de uma organização, tratadas como políticas infraestruturais.

As decisões estruturais, essencialmente, envolvem questões relacionadas à: capacidade, fornecimento, integração vertical, instalações, informação e tecnologia de processo (HAYES et al., 2008). Já as decisões infraestruturais descrevem as políticas e práticas que determinam os aspectos estruturais. Assim, a infraestrutura de uma organização governa uma série de atividades, desde orçamento financeiro e seleção de equipamentos até a estrutura organizacional.

Slack e Lewis (2011) apresentam três potenciais alternativas a serem acrescentadas às decisões infraestruturais que podem ser descritas em termos de estratégias de melhores práticas, estratégias de produção genéricas, competências e capacitações. As estratégias de melhores práticas fazem referência à utilização do JIT (just in time), TQM (total quality management), MRP I (material requeriment planning) e II (manufacturing resource 
planning), empowerment, dentre outras técnicas e programas, as quais no âmbito do planejamento e controle da produção evoluíram para outras abordagens, como por exemplo a Produção Enxuta.

Já as estratégias genéricas de manufatura abordam modelos que tratam a diferença de desempenho das operações por meio das técnicas de cluster, a citar os modelos de Weelwright (1984). E por último, as competências e capacidades tratam os fatores que promovem as habilidades distintas, provendo a superação das operações em relação aos concorrentes.

Vale observar, ainda, que de acordo com Skinner (1969) e Wheelright (1984) um conjunto de esforços devem ser desprendidos pela função produção para que as políticas infraestruturais alcancem as metas estabelecidas. De acordo com Ward, Leon e Boyer (1996) e Boyer e McDermott (1999), esses esforços podem ser alcançados por meio de políticas relacionadas à qualidade da liderança, delegação de responsabilidades e formação de equipes que, por sua vez, são interpretadas por meio dos elementos infraestruturais relacionados aos recursos humanos e à gestão organizacional.

\section{ABORDAGEM METODOLÓGICA}

Para o desenvolvimento do presente estudo, optou-se como método de pesquisa o levantamento de dados do tipo survey, o qual foi realizado na cidade de São Carlos. Essa cidade se destaca no cenário brasileiro por abrigar universidades (Universidade Federal de São Carlos-UFSCar; Universidade do Estado de São Paulo-USP) e centros de pesquisa (Empresa Brasileira de Pesquisa Agropecuária-EMBRAPA) reconhecidos por sua excelência e diversidade. Além disso, a cidade contempla empresas de diferentes segmentos e portes. Esse conjunto de características oferece a cidade um caráter acadêmico, tecnológico e industrial, permitindo que o título de Capital da Tecnologia seja a ela atribuído.

Em relação à população-alvo, entende-se que essa é representada pelas empresas que empregam de 20 a 99 funcionários. A considerar que o critério de classificação de empresas utilizado pela presente pesquisa se refere à classificação adotada pelo Instituto Brasileiro de Geografia e Estatística - IBGE, e o Serviço Brasileiro de Apoio às Micro e Pequenas Empresas - SEBRAE, as empresas estudadas foram tratadas como pequenas. Neste 
ponto, destaca-se que para a classificação delas, após a identificação das empresas inscritas no município de São Carlos, o número de funcionários foi aferido por meio de uma consulta no Cadastro Geral de Empregados e Desempregados - CAGED, resultando no total de 78 pequenas empresas inscritas no município.

Em relação ao dimensionamento amostral, embasado nos estudos de Rea e Parker (2002) e Costa Neto (2002) foi estabelecido que uma amostra com 37 empresas forneceria a precisão necessária da população total por ela representada. Já em relação ao tipo de amostragem e a técnica empregada, em razão da recusa de algumas em participar do estudo, o processo foi enquadrado como não probabilístico do caso de inacessibilidade a toda população (HINES; MONTGOMERY, 1990). Nota-se que diante dessa classificação a representatividade da amostra foi respeitada. Assim, embasado nos trabalhos de Lee e Valiant (1990) e Battaglia (2011), a atenuação dos eventuais desvios que poderiam ocorrer em função do tipo de amostragem pôde ser garantida pelo alinhamento e a semelhança entre a amostra e a população, promovendo a validade dos resultados inferidos e equivalem aos de uma amostra probabilística. Os Gráficos 1 e 2 que representam essas similaridades.

Gráfico 1 - Número de funcionários da população x amostra

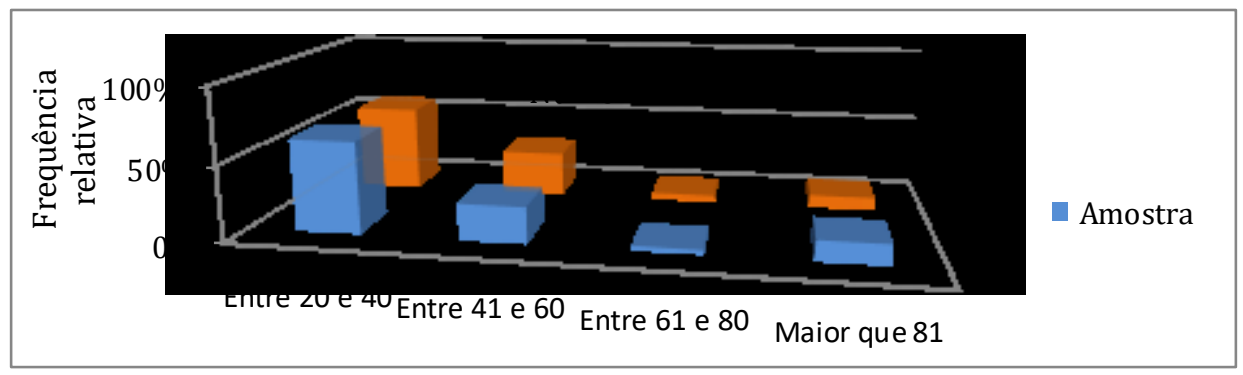

Fonte: Elaborado pelos autores com base nos dados da pesquisa (2020).

Gráfico 2 - Atividade econômica

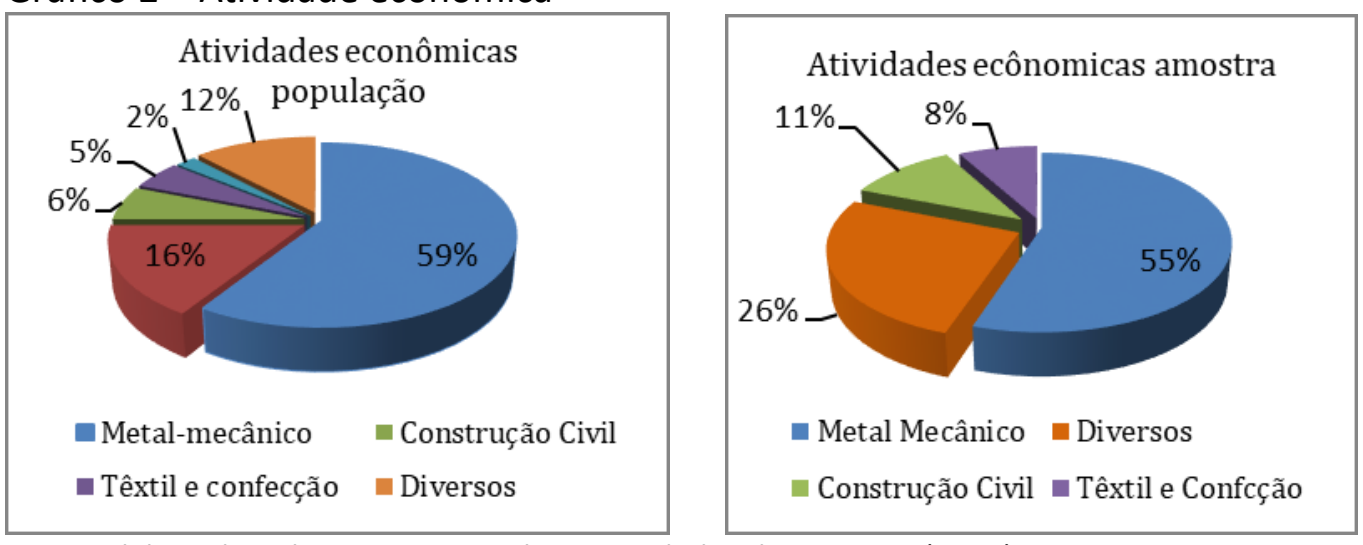

Fonte: Elaborado pelos autores com base nos dados da pesquisa (2020). 
Como técnica de pesquisa comum na condução de uma survey foi utilizada para coleta de dados um questionário estruturado (FORZA, 2002). A unidade de análise foi representada pela área de produção das pequenas empresas estudadas. Já a unidade de informação corresponde aos funcionários da área de produção, os quais foram representados pelos gerentes e operadores dessa área. Os Gráficos 1 e 2 apresentam uma visão geral das empresas, informando o número total de funcionários e o número de gerentes e operadores entrevistados.

Segundo Voss, Tsikriktsis e Frohlich (2002), para que houvesse convergência das informações, o reconhecimento de vieses e a adesão entre as observações e a realidade fossem respeitadas, os questionários foram aplicados pessoalmente pelos pesquisadores nas 38 empresas investigadas, totalizando 172 entrevistados, sendo 55 gerentes e 117 operadores.

Nota-se que a elaboração do questionário foi embasada na literatura e em estudos empíricos já realizados, de tal forma que as sentenças foram agrupadas em duas categorias: (i) características gerais da empresa e dos entrevistados e (ii) avaliação da importância dos elementos estratégicos na visão dos funcionários da área de produção. Para verificação da clareza, abrangência e aceitabilidade do questionário um pré-teste foi conduzido em 10 pequenas empresas. Desse modo, ajustes e o aperfeiçoamento do questionário foram realizados.

Em relação à primeira categoria, entende-se que as características gerais da empresa foram estabelecidas por meio de dezenove sentenças. Já a caracterização dos entrevistados foi realizada por meio de cinco sentenças, as quais foram aplicadas em grande parte aos gerentes. Nota-se que nem todas as sentenças e escalas atribuídas à caracterização das empresas e ao perfil dos gerentes foram aplicadas a todos os respondentes (gerentes e operadores).

Observa-se ainda que a construção dessas sentenças foi pautada nas características comumente tratadas pela literatura (seção 2.2) e por pesquisas já realizadas (BOYER; MCDERMOTT, 1999; MORAES, 2011), de modo que um conjunto de características identificadas pela literatura foi investigada na prática por meio de um conjunto de variáveis. 
O Quadro 1 sintetiza as características mais comumente tratadas pela literatura e apresenta as variáveis utilizadas para identificação do perfil das empresas estudadas.

Quadro 1 - Características das PME

\begin{tabular}{|c|c|c|c|}
\hline ID & Autores & $\begin{array}{c}\text { Característica } \\
\text { comumente tratada pela } \\
\text { literatura }\end{array}$ & $\begin{array}{l}\text { Variáveis utilizadas pela } \\
\text { presente pesquisa }\end{array}$ \\
\hline \multirow{6}{*}{$\mathrm{A} 1^{* * *}$} & \multirow{6}{*}{$\begin{array}{l}\text { Solomon (1986) } \\
\text { Ghobadian e Gallear (1997) } \\
\text { Leone (1999) } \\
\text { Curran (2006) }\end{array}$} & \multirow{6}{*}{$\begin{array}{l}\text { Vulnerabilidade aos } \\
\text { efeitos do ambiente } \\
\text { externo }\end{array}$} & Longevidade \\
\hline & & & $N^{\circ}$ de sócios \\
\hline & & & Níveis hierárquicos \\
\hline & & & $N^{\circ}$ de operadores \\
\hline & & & Atividade econômica \\
\hline & & & $\begin{array}{l}\text { Estratégia de Resposta a } \\
\text { Demanda }\end{array}$ \\
\hline $\mathrm{O} 1^{* *}$ & $\begin{array}{l}\text { Drucker (1992) } \\
\text { Ghobadian e Gallear (1997) } \\
\text { Leone (1999) } \\
\text { Curran (2006) } \\
\text { Alves Filho et al. (2010) }\end{array}$ & $\begin{array}{l}\text { Estrutura hierárquica } \\
\text { plana com poucos níveis } \\
\text { hierárquicos }\end{array}$ & Organograma da empresa \\
\hline $\mathrm{O} 2^{* *}$ & $\begin{array}{l}\text { Ghobadian e Gallear (1997) } \\
\text { Leone (1999) } \\
\text { Moraes e Escrivão Filho (2006) }\end{array}$ & $\begin{array}{l}\text { Canais de comunicação } \\
\text { simples (face-to-face) }\end{array}$ & $\begin{array}{l}\text { A maioria das instruções de } \\
\text { trabalho é transmitida aos } \\
\text { funcionários por meio de } \\
\text { comunicados por escrito e } \\
\text { reuniões formais }\end{array}$ \\
\hline O3** & $\begin{array}{l}\text { Cher (1991) } \\
\text { Ghobadian e Gallear (1997) } \\
\text { Leone (1999) } \\
\text { Moraes e Escrivão Filho (2006) } \\
\text { Alves Filho et al. (2010) }\end{array}$ & $\begin{array}{l}\text { Atividades de } \\
\text { planejamento informais }\end{array}$ & $\begin{array}{l}\text { Grau de formalização da } \\
\text { estratégia de produção }\end{array}$ \\
\hline O4** & $\begin{array}{l}\text { Leone (1999) } \\
\text { Alves Filho et al. (2010) }\end{array}$ & $\begin{array}{l}\text { Avaliação e controle } \\
\text { informais }\end{array}$ & $\begin{array}{l}\text { Identificação do número e } \\
\text { dos indicadores mais } \\
\text { utilizados pelas empresas }\end{array}$ \\
\hline G1* & $\begin{array}{l}\text { Drucker (1992) } \\
\text { Ghobadian e Gallear (1997) } \\
\text { Leone (1999) } \\
\text { Alves Filho et al. (2010) }\end{array}$ & $\begin{array}{l}\text { Poucos tomadores de } \\
\text { decisão }\end{array}$ & $\begin{array}{l}\text { O gerente consulta os } \\
\text { funcionários antes da } \\
\text { tomada de decisão }\end{array}$ \\
\hline & Almeida (1994) & & Gerente proprietário \\
\hline G2* & $\begin{array}{l}\text { Gonçalves e Koprowiski (1995) } \\
\text { Leone (1999) } \\
\text { Moraes e Escrivão Filho (2006) }\end{array}$ & $\begin{array}{l}\text { Trabalho próprio ou de } \\
\text { familiares }\end{array}$ & $\begin{array}{l}\text { Gerente apresenta grau de } \\
\text { parentesco com } \quad \text { o } \\
\text { proprietário ou sócio }\end{array}$ \\
\hline G3* & $\begin{array}{l}\text { Solomon (1986) } \\
\text { Alves Filho et al. (2010) }\end{array}$ & $\begin{array}{lll}\begin{array}{l}\text { Tomada } \\
\text { intuitiva }\end{array} & \text { decisão } \\
\end{array}$ & $\begin{array}{l}\text { Nivel de conhecimento de } \\
\text { gestão dos gerentes }\end{array}$ \\
\hline G4* & $\begin{array}{l}\text { Cher (1991) } \\
\text { Ghobadian e Gallear (1997) } \\
\text { Curran (2006) }\end{array}$ & $\begin{array}{l}\text { Grande influência do } \\
\text { proprietário-dirigente }\end{array}$ & $\begin{array}{l}\text { A proximidade do } \\
\text { proprietário com gerentes e } \\
\text { operadores facilita a } \\
\text { execução dos trabalhos } \\
\text { diários }\end{array}$ \\
\hline
\end{tabular}

Fonte: Adaptado de Alves Filho et al. (2010).

*G1 a G4 referem-se às perspectivas gerenciais

** 01 a 011 referem-se às perspectivas organizacionais

***A1 refere-se à perspectiva do ambiente 
No que se refere à segunda categoria, a qual busca estabelecer a ordem de importância dos elementos centrais da estratégia de produção na percepção dos funcionários da área de produção, um conjunto de constructos foi estabelecido por meio do desdobramento das seguintes variáveis: prioridades competitivas, investimentos estruturais e políticas infraestruturais. A elaboração desse questionário foi embasada no trabalho já desenvolvido por Boyer e McDermott (1999). Logo, um conjunto de prioridades comumente tratadas pela literatura para representar as variáveis prioridades competitivas foram elencadas. Para as variáveis que representam os investimentos estruturais um conjunto de constructos relacionados à Tecnologia de Manufatura Avançada (AMT) foi utilizado, os quais foram originalmente desenvolvidos por Boyer, Ward e Leong et al. (1996) e validados por Boyer e McDermott (1999). Neste ponto, destaca-se que a importância da investigação das AMT em pequenas empresas como elemento representativo da área estrutural, além de estar apoiada nos estudos de Boyer e McDermott (1999).

Quanto à análise dos dados, para o desenvolvimento do presente estudo, optou-se pela abordagem quantitativa por meio do emprego de um conjunto de técnicas estatísticas (COSTA NETO, 2002). O uso dessas técnicas foi viabilizado por um ferramental estatístico (Statistical Package for the Social Science ${ }^{\circledR}$ - SPSS).

Em relação às técnicas destaca-se o uso de Análise Estatística Descritiva, de modo que foram utilizados gráficos, tabelas e medidas descritivas (medidas de tendência central e dispersão). Para complementar tais análises e validar as inferências realizadas foram também empregados testes de hipóteses para a proporção populacional, testes de hipóteses para a comparação de diferentes médias através da Análise de Variância (ANOVA) e testes Post Hoc.

\section{RESULTADOS E DISCUSSÕES}

As análises realizadas permitiram traçar o perfil das pequenas empresas, as quais foram representadas pelas pequenas empresas da cidade de São Carlos. Para facilitar o entendimento e a apresentação dos resultados, os mesmos foram organizados em três grupos: (i) características organizacionais, (ii) perfil dos gerentes e (iii) a importância dos elementos estratégias nas pequenas empresas de São Carlos. 
Quanto às características organizacionais, os primeiros dados sobre as pequenas empresas de São Carlos referem-se à longevidade das mesmas no mercado, o número de sócios, os níveis hierárquicos que definem a sua estrutura organizacional e o número de operadores (funcionários alocados diretamente na área de produção).

A síntese das estatísticas descritivas para as variáveis citadas acima encontra-se na Tabela 1.

Tabela 1 - Estatística descritiva das empresas que compõem a amostra

\begin{tabular}{|c|c|c|c|c|c|c|}
\hline Variável & 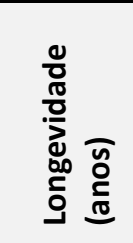 & 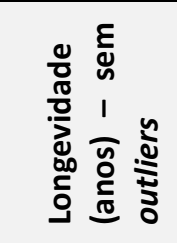 & 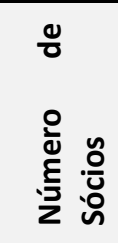 & 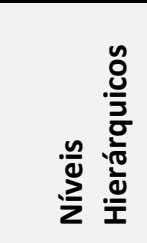 & 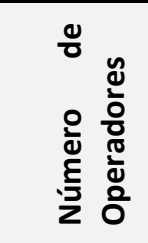 & 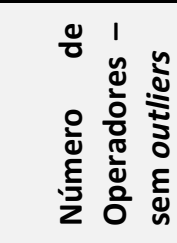 \\
\hline Média & 23,7 & 19,6 & 1,9 & 2,9 & 35,5 & 31,6 \\
\hline Mediana & 19,5 & 19,0 & 2,0 & 3,0 & 31,0 & 31,0 \\
\hline Mínimo & 2 & 2 & 0 & 2 & 19 & 10,6 \\
\hline Máximo & 98 & 41 & 5 & 6 & 81 & 19 \\
\hline Desvio Padrão Amostral & 17,9 & 9,9 & 1,1 & 1,1 & 16,7 & 10,6 \\
\hline Coeficiente de Variação & $70,5 \%$ & $50,5 \%$ & $57,9 \%$ & $37,9 \%$ & $47,0 \%$ & $35,5 \%$ \\
\hline
\end{tabular}

Fonte: Elaborado pelos autores com base nos dados da pesquisa (2020).

Em relação à longevidade dessas empresas, verificou-se que aproximadamente $80 \%$ das pequenas empresas de São Carlos possuem mais de 10 anos no mercado (Gráfico 3a), sendo que $19 \%$ apresenta possivelmente mais de 30 anos. Os Gráficos 3a e 3b apresentam a distribuição dessa variável.

Gráfico 3a e 3b - Histogramas para a longevidade com outliers e sem outliers

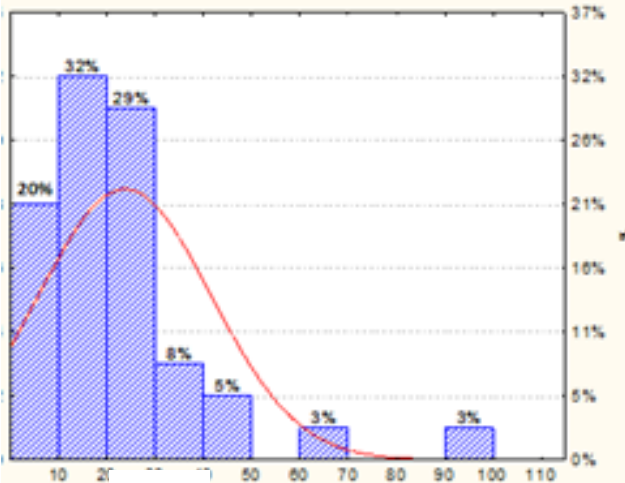

(a)

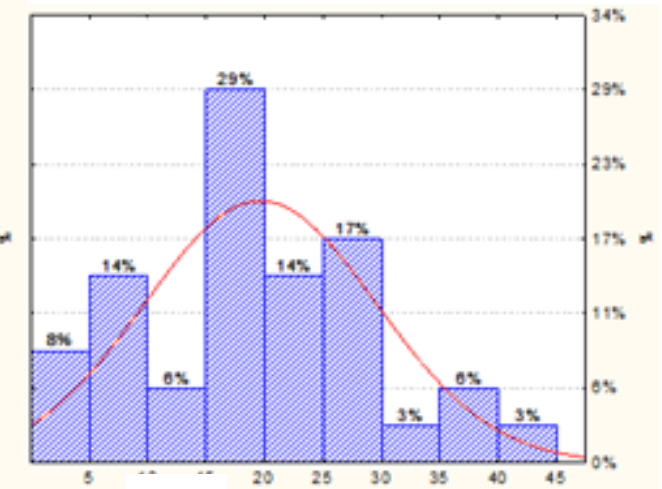

(b)

Fonte: Elaborado pelos autores com base nos dados da pesquisa (2020).

A análise do Gráfico 3a permitiu ainda observar uma significativa assimetria, a qual sugere a presença de potenciais outliers. Nota-se que a diferença entre a média e mediana, 
como foi possível observar na Tabela 1 foram bons indicativos de valor extremos na amostra (COSTA NETO, 2002).

Em relação ao número de sócios, o maior percentual, 47,36\%, refere-se às empresas que possuem 2 sócios, seguido por 26,31\% com 3 sócios, 13,15\% com apenas um sócio e 2,63\% empresas que possuem 4 sócios ou mais. Somam-se a esses percentuais, 10,56\% das empresas que declararam não possuir sócios. Nota-se ainda que ao considerar como um grupo, as empresas que possuem dois ou três sócios atingiu o percentual de aproximadamente $74 \%$, sendo esse um indicativo da forma predominante com a qual essas empresas se formam: associação de mais de uma pessoa interessada em desenvolver uma atividade fim.

Em relação à formalização da estratégia de produção, tendo como base a classificação proposta por Bracker e Pearson (1986), verificou-se, conforme demonstrado no Gráfico 4, que a expressiva maioria das pequenas empresas realiza as atividades de planejamento de maneira informal. Além disso, na medida em que aumenta a sofisticação do planejamento, em termos de formalidade, a participação dessas pequenas empresas diminui. Essa constatação é coerente com a literatura específica da área e revisada na seção 2.

\section{Gráfico 4 - Formalização da estratégia de produção para empresas da amostra}

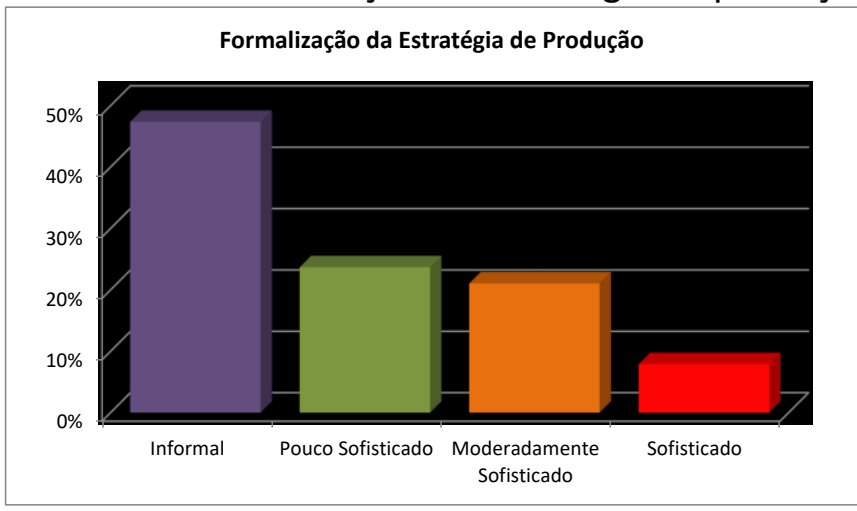

Fonte: Elaborado pelos autores com base nos dados da pesquisa (2020).

Outra característica investigada nas PME de São Carlos refere-se ao processo de comunicação interna. Assim, foram analisadas as percepções médias de múltiplos respondentes para cada um dos quatro construtos associados ao canal de comunicação. Diante do exposto, os funcionários da área de produção foram questionados quanto à 
formalidade, aos conflitos e à influência da interferência direta do proprietário nas atividades de rotina dos operadores.

A interpretação das respostas oriundas da survey a respeito da escala proposta foi no seguinte sentido: quanto maiores os escores, mais evidente foram as características investigadas nos canais de comunicação interna e a exceção aplicou-se ao constructo "a", visto que quanto maior o escores mais evidente foi a formalidade.

Os resultados obtidos em termos de estatística descritiva encontram-se na Tabela 2.

Tabela 2 - Estatística descritiva sobre os processos de comunicação internos das empresas que compõem a amostra

\begin{tabular}{|c|c|c|c|c|c|c|c|c|}
\hline \multirow{2}{*}{ Constructos } & \multicolumn{5}{|c|}{ Gerentes } & \multicolumn{3}{|c|}{ Operadores } \\
\hline & $\bar{x}$ & Md & $s$ & $c v$ & $\bar{x}$ & md & $s$ & $c v$ \\
\hline $\begin{array}{l}\text { (a) A maioria das instruções de } \\
\text { trabalho é transmitida aos } \\
\text { funcionários através de comunicados } \\
\text { por escrito e reuniões formais. }\end{array}$ & 4,49 & 5,0 & 2,32 & 51,76 & 4,54 & 5,0 & 2,05 & 42,24 \\
\hline $\begin{array}{l}\text { (b) Informações e orientações } \\
\text { transmitidas apenas de modo verbal } \\
\text { potencializam conflitos pessoais. } \\
\text { (c) Informações e orientações }\end{array}$ & 4,38 & 5,0 & 2,06 & 46,99 & 4,64 & 5,0 & 2,10 & 45,34 \\
\hline $\begin{array}{l}\text { transmitidas apenas de modo verbal } \\
\text { geram imprecisão nos resultados. }\end{array}$ & 4,49 & 5,0 & 2,03 & 45,33 & 4,47 & 5,0 & 2,23 & 49,73 \\
\hline $\begin{array}{l}\text { (d) A proximidade do proprietário com } \\
\text { gerentes e operadores facilita a } \\
\text { execução dos trabalhos diários. }\end{array}$ & 5,83 & 6,0 & 1,59 & 27,34 & 6,19 & 6,0 & 1,36 & 22,04 \\
\hline
\end{tabular}

Fonte: Elaborado pelos autores com base nos dados da pesquisa (2020).

Os resultados referentes aos constructos descritos na Tabela 2 evidenciam similaridades na forma como gerentes e operadores avaliam à comunicação interna. Estatisticamente, não é possível rejeitar a hipótese de igualdade entre as notas atribuídas pelos gerentes e operadores para todos os constructos investigados. Essa foi à conclusão da ANOVA um fator, ao nível de significância de $1 \%$.

Acrescenta-se a essas constatações que os valores das médias atribuídas por gerentes e operadores foram em um nível mediano a alto. Essa constatação permitiu apontar que em relação ao primeiro constructo, nas percepções de gerentes e operadores, a maioria das instruções de trabalho foi transmitida aos funcionários por meio de comunicados formais. Tal constatação se afasta dos apontamentos encontrados na literatura específica das PME (GHOBADIAN; GALLEAR, 1997; MORAES; ESCRIVÃO FILHO, 2006), 
sugerindo que as pequenas empresas de São Carlos apresentaram medianos para a formalização dos seus canais de comunicação interna.

Nos demais constructos (b, c e d), os quais investigaram o impacto da informalidade nas operações de rotina de gerentes e operadores, também foram observados valores medianos a alto. Esses valores sugerem que embora exista uma tendência na formalização dos canais de comunicação (constructo a), a necessidade de uma estreita colaboração entre o proprietário, gerentes e operadores foi alta. Vale observar que esse comportamento também foi observado no trabalho de Leone (1999), o qual destaca que, por vezes, os proprietários e gerentes assumem um comportamento paternalista e, por circunstância, egocêntrico, uma ocorrência que criam e até mesmo estimulam a necessidade desse relacionamento estreito e dependente.

Para averiguar as percepções dos funcionários quanto à descentralização do processo decisão em PME, tratado pela literatura da área como uma especificidade intrínseca às ações gerenciais (DRUCKER, 1992; GHOBADIAN; GALLEAR, 1997; LEONE, 1999; ALVES FILHO et al., 2010), os respondentes foram questionados quanto ao grau de concordância em relação à participação dos funcionários nas decisões sobre a produção. A avaliação dessa questão ocorreu com base na nota média dos respondentes, os quais foram divididos em dois grupos: gerentes e operadores.

Desse modo, constatou-se o valor médio de 4,7 e desvio padrão de 1,7 para avaliação dos gerentes e o valor médio de 4,3 e desvio padrão de 1,8 para operadores. Vale observar que, apesar de não ser possível rejeitar estatisticamente a hipótese de igualdade, os valores atribuídos para os gerentes foram superiores aos valores atribuídos aos gerentes, o que sinalizou que eles atribuíram maior participação aos operadores que esses acreditam ter.

Nota-se, ainda, que o escore atribuído indica, quanto maior o escore mais evidente foi a característica de tomada de decisão centralizada. No presente caso, os escores obtidos foram próximos aos valores médios, indicando um ponto intermediário entre o totalmente centralizado e o descentralizado.

Quanto ao perfil dos gerentes, a literatura específica sobre esse porte de empresa reconhece que as características dos mesmos são uma das perspectivas centrais para o 
entendimento das PME. Vale observar que na presente pesquisa, o termo gerentes inclui dirigentes, proprietários e demais funcionários que assumem uma posição gerencial formal no organograma da empresa.

Os seguintes pontos caracterizaram o perfil dos gerentes das pequenas empresas de São Carlos que participaram do estudo:

a) Existe uma nítida predominância dos gerentes do gênero masculino, representando, aproximadamente, $85 \%$ dessa classe, sendo que $67,4 \%$ desses possuem nível superior, conforme mostra o Gráfico 5b. Apesar dos gerentes do sexo masculino representar a maioria, notou-se que há uma diferença significativa entre o percentual de gerentes do sexo feminino que apresentam nível superior em relação ao sexo oposto, chegando a $78 \%$;

b) Considerando os gerentes do gênero feminino e masculino como um grupo, observou-se uma predominância significativa de gerentes com nível superior, representado aproximadamente $70 \%$ do total, conforme o Gráfico 5b;

c) A média do tempo da empresa dos gerentes foi de, aproximadamente, 16 anos, com desvio-padrão de 13,51 , resultando no coeficiente de variação de cerca de $85 \%$. Tal valor expressou significativa heterogeneidade quanto ao tempo de empresa dos gerentes (COSTA NETO, 2002), não sendo possível, portanto, traçar um perfil claro deles nas pequenas empresas de São Carlos, no que toca essa variável;

d) Aproximadamente, $42 \%$ dos gerentes apresentam algum grau de parentesco com o proprietário. Ademais, aproximadamente, 48\% são também sócios. Esses números foram indicativos de que o ambiente das pequenas empresas de São Carlos ainda foi muito marcado por vínculos familiares, portanto, há grande concordância com a literatura específica sobre o tema (CHER, 1991; ALMEIDA, 1994; LEONE, 1999). 
Gráfico 5a e 5b - Escolaridades dos gerentes nas empresas da amostra

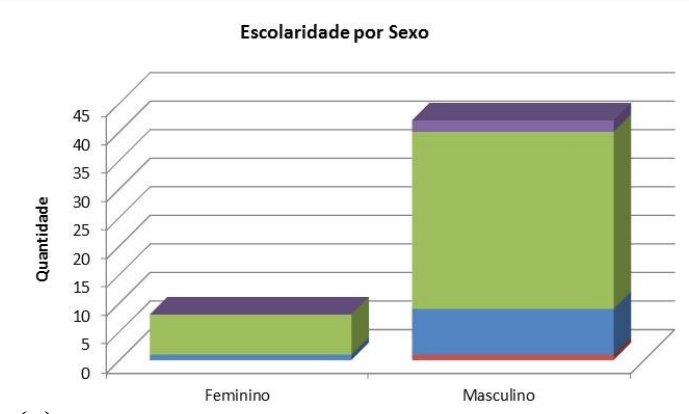

(a)

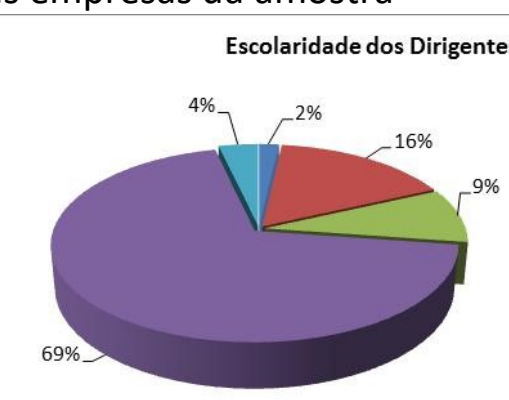

Ensino Fundamental

- Ensino Médio

- Nivel Técnico

- Curso Superior

- Pós-graduação

Fonte: Elaborado pelos autores com base nos dados da pesquisa (2020).

Além dessas características, inspirado nos estudos que sugerem o processo de tomada de decisão intuitivo é motivado pela escassez de conhecimento técnico e de gestão (SOLOMON, 1986; MORAES; ESCRIVÃO FILHO, 2006), o nível de conhecimento dos gestores em relação aos modelos de estratégias de produção e técnicas de gestão foram identificados por meio de um check list.

Notadamente, a Competição Baseada no Tempo, Customização em Massa e a Manufatura Ágil foram três fatores que os resultados apontam como desconhecidos. Observou-se, portanto, que os modelos estratégicos de produção mais recentes foram os menos difundidos entre os gerentes de pequenas empresas da amostra. Neste ponto, retomam-se os apontamentos de Solomon (1986) que asseveram que a capacidade limitada de gestão estratégica foi um dos pontos fracos da gestão realizada pelos gerentes das PME.

Inspirado nas recomendações de Skinner (1969) e Wheelwright (1978) quanto a importância dos elementos estratégicos para o sucesso de uma estratégia de produção, a presente pesquisa buscou estabelecer dentre os três elementos estratégicos centrais (prioridades competitivas, investimentos estruturais e infraestruturais) qual apresenta prioridade em termos de importância na percepção dos funcionários da área de produção.

Para iniciar a apresentação dos resultados obtidos, apresenta-se na Tabela 3 a síntese de diferentes estatísticas descritivas relacionadas aos escores atribuídos para os elementos que representaram as prioridades competitivas, investimentos estruturais e políticas infraestruturais. 
Tabela 3 - Estatística descritiva para as prioridades competitivas, investimentos estruturais e políticas infraestruturais das empresas que compõem a amostra

\begin{tabular}{|c|c|c|c|c|c|}
\hline \multirow{2}{*}{\multicolumn{2}{|c|}{ Elementos estratégicos }} & \multicolumn{4}{|c|}{ Respondentes } \\
\hline & & \multirow{2}{*}{$\begin{array}{l}\bar{x} \\
5,00\end{array}$} & \multirow{2}{*}{$\begin{array}{r}\text { md } \\
5,13\end{array}$} & \multirow{2}{*}{$\begin{array}{r}s \\
1,28\end{array}$} & \multirow{2}{*}{$\begin{array}{l}c v(\%) \\
25,66\end{array}$} \\
\hline \multirow{6}{*}{$\begin{array}{l}\text { Prioridades } \\
\text { Competitivas }\end{array}$} & Custo & & & & \\
\hline & Qualidade & 6,14 & 6,67 & 1,16 & 18,88 \\
\hline & Entrega & 5,90 & 6,33 & 1,26 & 21,45 \\
\hline & Flexibilidade & 5,14 & 5,50 & 1,55 & 30,17 \\
\hline & Inovação & 5,65 & 6,00 & 1,21 & 21,50 \\
\hline & Geral & 5,57 & & & \\
\hline \multirow{4}{*}{$\begin{array}{l}\text { Investimentos } \\
\text { Estruturais }\end{array}$} & Projeto & 3,71 & 4,00 & 1,50 & 40,59 \\
\hline & Produção & 2,81 & 2,71 & 1,23 & 43,73 \\
\hline & Administração & 3,81 & 4,00 & 1,19 & 31,23 \\
\hline & Geral & 3,44 & & & \\
\hline \multirow{4}{*}{$\begin{array}{l}\text { Políticas } \\
\text { Infraestruturais }\end{array}$} & WEMP & 5,88 & 6,07 & 0,85 & 14,55 \\
\hline & QLead & 4,90 & 5,00 & 1,12 & 22,77 \\
\hline & Team & 4,32 & 5,00 & 2,11 & 48,88 \\
\hline & Geral & 5,03 & & & \\
\hline
\end{tabular}

Fonte: Elaborado pelos autores com base nos dados da pesquisa (2020).

Diante da Tabela 3, é possível visualizar uma diferença da importância média atribuída para cada um dos grupos de elementos estratégicos. Essa constatação foi confirmada por meio do teste de hipóteses de comparação de médias ANOVA, um fator ao nível de significância 1\%, quando foi rejeitada a hipótese de igualdade entre as médias. Os testes post hoc apontaram que as três médias diferem entre si (diferentes testes realizados a um mesmo nível de significância).

Os resultados obtidos por meio dos testes mencionados permitem estabelecer que o elemento estratégico mais destacado pelos funcionários é a prioridade competitiva, seguido de política infraestrutural e do investimento estrutural.

A priorização do primeiro conjunto de elementos estratégicos por parte dos funcionários quando comparado aos demais indicam que a importância no estabelecimento de metas (relacionadas a esse primeiro grupo de elementos), tratadas, por vezes, pela literatura como objetivos ganhadores de pedido e qualificadores (SLACK; LEWIS, 2011), estão presentes nas discussões e rotina dos funcionários. Assim, como estiveram salientadas nas discussões acadêmicas, uma vez que aproximadamente $65 \%$ dos trabalhos que investigaram a estratégia de produção em PME tratam das prioridades competitivas.

Já quanto às áreas de decisão, os resultados indicaram que a mesma importância não foi dada à configuração dessas áreas. Isso sugere que as pequenas empresas apresentaram 
dificuldades quanto à identificação da importância dos elementos estruturais e infraestruturais necessários para o alcance das metas estabelecidas, principalmente, no que se referiu à área estrutural. Tal constatação chama a atenção, uma vez que a literatura (GUPTA; CAWTHON, 1996; ABDUL-NOUR; LAMBERT; DROLET, 1998) trata o uso de tecnologias em PME (investigadas através do grupo de elementos estruturais) como uma alternativa à limitação de recursos vivenciada por essas empresas. Desse modo, é possível afirmar que, embora a literatura aponte o uso das tecnologias em PME como solução aos problemas por elas enfrentados, esses resultados revelam que essa ainda é uma realidade distante das PME, pelo menos no que diz respeito às pequenas empresas de São Carlos.

É válido, ainda, destacar que, embora os testes revelaram significância estatística para a diferença das três médias que mensuram os elementos estratégicos investigados, a importância atribuída ao elemento infraestrutural, apesar de apresentarem menor grau do que o apontado para as prioridades competitivas, está muito próximo desse e muito distante do grupo dos elementos estruturais. Isso sugere um movimento das PME em termos de superação de suas dificuldades, em relação aos processos de aprendizado, aperfeiçoamento e busca de melhores práticas (LEONE, 1999; MORAES; ESCRIVÃO FILHO, 2006). No entanto, esse movimento de superação das PME parece estar limitado pelos problemas financeiros que essas empresas vivenciam (LEONE, 1999; MORAES; ESCRIVÃO FILHO, 2006), impedindo que os avanços em termos de configuração da área infraestrutural sejam os mesmos para a área estrutural.

Desse modo, é possível concluir que as recomendações apontadas pela literatura quanto à importância do uso de tecnologias em PME não são incorporados ao dia a dia dessas empresas. Somam-se a essas observações, os relatos dos gerentes que, no decorrer das entrevistas realizadas, sinalizaram que as razões para os baixos investimentos em tecnologia estão associadas a falta de incentivos governamentais e a burocratização a que essas empresas estão suscetíveis.

\section{CONSIDERAÇÕES FINAIS}

Este trabalho propôs-se a identificar os fatores que influenciam um maior ou menor grau de consenso da estratégia de manufatura, a montante e a jusante (antes, dentro e 
depois da porteira), analisando o nível de alinhamento entre os diferentes funcionários envolvidos na definição de uma estratégia de produção em pequenas empresas que operam na economia emergente.

Primeiramente, se destaca a longevidade das empresas, aproximadamente, $80 \%$ das pequenas empresas possuem mais de 10 anos. Outra característica que se destaca, refere-se ao número de sócios, visto que aproximadamente $90 \%$ declararam possuir de 2 a 4 sócios, desses $48 \%$ afirmam exercer funções gerencias. A simplicidade estrutural foi corroborada e 48\% das empresas apresentam apenas dois níveis hierárquicos.

O número de funcionários alocados diretamente na área de produção também foi verificado, correspondendo de 70 a $90 \%$ do total de funcionários. A atividade econômica predominante nas pequenas empresas estudadas é representada pelo setor metalmecânico, representando 55\%, seguido de outros setores como a agroindústria. A estratégia de resposta a demanda predominante é a produção sob encomenda, totalizando aproximadamente $40 \%$ das pequenas empresas. A informalidade no planejamento da produção também foi expressiva, pois $50 \%$ das empresas investigadas declararam um planejamento inexistente ou intuitivo.

Além desse ponto, destacou-se a participação (aproximadamente em $50 \%$ das empresas) dos proprietários e familiares no dia a dia dessas empresas. Soma-se, a essas inferências a simplicidade apresentada pelas pequenas empresas de São Carlos em termos de estrutura organizacional (novamente, aproximadamente $50 \%$ das empresas), apresentando apenas dois níveis hierárquicos. A pesquisa realizada revelou ainda que a interferência do proprietário na gestão da empresa tem efeitos positivos no desempenho das atividades diárias e resultados alcançados.

No que se refere ao perfil dos gerentes, destaca-se que são em grande maioria homens (85\%). No entanto, os gerentes do sexo feminino apresentaram maior nível de escolaridade. Já quanto ao Know-how desses gerentes em termos de estratégia de produção e técnicas de gestão, verifica-se que o modelo estratégico mais difundido entre os gerentes é a Manufatura em Massa, o que se contrapõem ao conhecimento ínfimo de técnicas de gestão mais modernas, tais como: Competição Baseada no Tempo e Manufatura Ágil. 
Em relação as constatações que se afastam dos apontamentos encontrados na literatura, destacam-se a formalidade nos canais de comunicação, para a qual foi atribuída um valor médio com tendência a alto, indicando que a maioria dos comunicados e orientações de trabalho são transmitidas de maneira formal ou por escrito.

Acrescenta-se a essas conclusões, o resultado das análises em relação à importância de cada um dos grupos de elementos estratégicos (prioridades competitivas, investimentos estruturais e políticas infraestruturais) nas percepções dos funcionários da área de produção. Assim, a comparação em termos de priorização para esses três conjuntos de elementos permitiu estabelecer que o grupo de prioridades competitivas é o que apresentou o maior escore de importância quando comparado aos demais. Já o grupo de elementos estruturais foram tratados como os menos importantes pelos entrevistados. Tal verificação mostra que, embora a literatura indique que as pequenas empresas devem investir em AMT para superarem as dificuldades enfrentadas no que se refere à escassez de recursos de mãode obra e a falta de know-how (GUPTA; CAWTHON, 1996; ABDUL-NOUR, LAMBERT, DROLET, 1998), a escassez de recursos financeiros a que essas empresas estão suscetíveis inviabiliza tais investimentos, de modo que a ausência desses repercutem nas percepções de importância dos entrevistados.

Já em relação à importância das políticas infraestruturais, observou-se que a diferença foi significativa quando comparada aos elementos estruturais. A razão disso pode estar associada novamente às questões financeiras. Diferentemente dos elementos estruturais, a adoção de políticas na área infraestrutural não é tão dispendiosa, tornando-a factível a realidade dessas empresas. Desse modo, as pequenas empresas apresentam maior capacidade para adotá-las, o que as tornam mais visíveis aos funcionários. E, por conseguinte, apresentam maior ponderação de importância.

Diante dos resultados apresentados, acredita-se que a pesquisa tenha contribuído para um melhor entendimento da realidade das pequenas empresas, de modo a auxiliar gestores e pesquisadores em termos de ferramentas e modelos de gestão que melhor se adequem a realidade das pequenas empresas. 
Em termos de trabalhos futuros existem algumas linhas que podem ser seguidas. A primeira refere-se à ampliação da população de estudo a outras cidades do entorno, de modo que demais regiões sejam incluídas nesse estudo. Outra linha poderia ser à inclusão de outras variáveis e critérios para a representação do conjunto de elementos estratégicos investigados, especialmente, em relação à área estrutural e infraestrutural.

O resultado desse trabalho também pode servir como uma amostra para aqueles agroempresários que se dedicam a aplicar a Agricultura 4.0, devendo observar alguns preceitos como os resultados dessa pesquisa, com o intuito de viabilizar essa mudança de patamar em sua estratégia de produção, obtendo assim melhores resultados.

Esses tópicos que ainda podem ser explorados e os resultados obtidos são uma prova que novos estudos em pequenas empresas, principalmente pela emergência de temas como Crescimento Exponencial, Indústria e Agricultura 4.0, podem contribuir tanto do ponto de vista acadêmico, como também, em um cenário de desafios econômicos, para a obtenção de vantagens competitivas por essas empresas.

\section{REFERÊNCIAS}

ABDUL-NOUR, G.; LAMBERT, S.; DROLET, J. Adaptation of JIT philosophy and Kanban technique to a small-sized manufacturing firm: a project management approach Computers \& Industrial Engineering 35 (3-4), 419-422. 1998.

ALMEIDA, M. I. R. Desenvolvimento de um modelo de planejamento estratégico para grupos de pequenas empresas 1994. $118 \mathrm{f}$. Tese (Doutorado em Administração) - Faculdade de Economia, Administração e Contabilidade, Universidade de São Paulo, São Paulo. 1994.

ALVES FILHO, A. G.; ESCRIVÃO FILHO, E.; TERENCE, A. C.; RAMALHO, A. M.; C.R., LACERDA, D. P. Estratégia na prática de grandes e de pequenas empresas. In: OLIVEIRA, V. F., CAVENACHII, V., MÁSCULO, F. S (Orgs). Tópicos emergentes e desafios metodológicos em engenharia de produção: casos, experiências e proposições. Rio de Janeiro: Associação Brasileira de Engenharia de Produção, (4), 89-149, 2010.

ARANGÓN-SÁNCHEZ, A.; SÁNCHEZ-MARÍN, G. Strategic orientation, management characteristics, and performance: a study of Spanish SMEs. Journal of Small Business Management 43 (3), 278-308, 2005.

ASC, Z. J.; PRESTON, L. Small and medium-sized enterprises, technology, and globalization: introduction to a special issue on small and medium-sized enterprises in the global economy small. Business Economics 9 (1), 1-6, 1997 
BATTAGLIA, M. P. Nonprobability Sampling. Encyclopedia of Survey Research Methods, SAEG Publications, 2011.

BOYER, K. K.; MCDERMOTT, C. Strategic consensus in operations strategy. Journal of Operations Management, 17 (5), 289-305, 1999.

BOYER, K.K.; PAGELL, M. Measurement issues in empirical research: improving measures of operations strategy and advanced manufacturing technology, Journal of Operations Management, 18 (3), 361-374, 2000.

BOYER, K. K.; WARD, P. T.; LEONG, G. K. Approaches to the factory of the future: an empirical taxonomy. Journal of Operations Management 14 (4), 297-313, 1996.

BROUTHERS, K. D.; NAKOS, G.; DIMITRATOS, P. SME entrepreneurial orientation, international performance, and the moderating role of strategic alliances.

In: Entrepreneurship Theory and Practice, v. 39, n. 5, p. 1161-1187, 2015. Disponível em: <https://onlinelibrary.wiley.com/doi/abs/10.1111/etap.12101>. Acesso em: 26 de jul. 2018.

BRACKER, J. S.; PEARSON, J. N. Planning and financial performance of small, mature firms. Strategic Management Journal 7 (6), 503-522, 1986.

BRAGUIER, I. Le comportement organisationnel et strategique de PME: I' effect de l' incertitude perçue de I' environnemnt. 1993. Tese (Doutorado) - Université de Poirtiers (IAE), Poitiers, 1993.

CALLADO, A. A. C. ; CALLADO, A. L. C. Custos: um desafio para a gestão no agronegócio. In... Anais do Congresso Brasileiro de Custos-ABC. 1999.

CHER, R. A gerência das pequenas e médias empresas. São Paulo: Maltese, 1991.

COSTA NETO, P. L. O. Estatística. (3ed.) São Paulo: Blucher, 2002.

CURRAN, J. Specificity and denaturing the small business. International Small Business Journal 24 (2), 205-210, 2006.

DA SILVA, E. M.; ALVES, L. F. N. Organização e diversidade dos sistemas de produção de agricultores familiares integrados à agroindústria de dendê no nordeste Paraense. Revista Brasileira de Gestão e Desenvolvimento Regional, 14 (1), 166-192, 2018.

DRUCKER, P. F. A prática da administração de empresas. São Paulo: Pioneira, 1992.

DUBEY, R.; GUNASEKARAN, A.; CHAKRABARTY, A. World-class sustainable manufacturing: framework and a performance measurement system. International Journal of Production Research, 53(17), 5207-5223, 2015.

FOgUeSATO, C. R.; MÜLlER, F. M.; ARTUZO, F. D.; MACHADO, J. A. D. Cenários de agregação de valor ao produto: proposta de criação de uma agroindústria familiar. Custos e

@gronegócio on line. 14 (2), 390-409, 2018. 
FORZA, C. Survey research in operations management: a process-based perspective. International Journal of Operations \& Production Management, 22 (2), 152-194. 2002.

FNQ. Cadernos de Excelência: introdução ao modelo de excelência da gestão. São Paulo: Fundação Nacional da Qualidade, 2008.

GHOBADIAN, A.; GALLEAR, D. TQM and organization size. International Journal of Operations \& Production Management, 17 (2), 121-163, 1997.

GOMES RODRIGUES. G. L.; SEIDE FROEMMING, L. M.; SEHNEM, S. O relacionamento de indústrias leiteiras com seus Stakeholders externos com abordagem da Matriz Estratégica de Agribusiness (MEA). Estudos Sociedade e Agricultura, 24 (1), 2016.

GONÇALVES, A.; KOPROWSKI, S. O. Pequena empresa no Brasil. São Paulo: EDUSP, 1995.

GUPTA, M; CAWTHON, G. Managerial implications of flexible manufacturing for small \medium-sized enterprises. Technovation, 16 (2), 77-83, 1996.

HAYES, R. H.; PISANO, G.; UPTON, D.; WHEELWRIGHT, S. Operations, strategy, and technology: pursuing the competitive edge. New York: John Wiley \& Sons, 2008.

HINES, W.W.; MONTGOMERY, D.C. Probability and Statistics in Engineering and Management Science. John Wiley \& Sons. New York, NY, 732, 1990.

IBGE. Demografia das empresas. Rio de Janeiro, 2017. Disponível em: < https://biblioteca.ibge.gov.br/visualizacao/livros/liv101151.pdf>. Acesso em: 06 abr. 2018.

LEE, S.; VALLIANT, R., R. Estimation for Volunteer Panel Web Surveys Using Propensity Score Adjustment and Calibration Adjustment. Sociological Methods \& Research, 37(3), 319-43, 1990.

LEONE, N. M. C. P. G. A dimensão física das pequenas e médias empresas: a procura de um critério homogeneizador. Revista de Administração, 31 (2), 53-59, 1999.

LOUBET, L. F. Tributação Federal no Agronegócio. 2009. 819 f. Dissertação (Mestrado em Direito). Pontifícia Universidade Católica de São Paulo, PUC, São Paulo, 2009.

LOPES, A. C. V.; KNIESS, C. T.; RAMOS, H. R. Fatores que influenciam a adoção do balanced scorecard (BSC) em uma cooperativa agroindustrial: um estudo com base na teoria de difusão de inovação. Iberoamerican Journal of Strategic Management (IJSM), 14 (3), 131 144, 2015.

MORAES, G. D. A.; ESCRIVÃO FILHO, E. O ciclo vicioso na gestão de pequenas empresas: uma análise do processo estratégico e operacional. In: ENCONTRO NACIONAL DE ENGENHARIA DE PRODUÇÃO, Fortaleza. Anais... Fortaleza: ABEPRO, 81- 102, 2006.

MORAES, G. D. A. Alinhamento da estratégia do negócio e da TI na pequena empresa: uma análise dos fatores facilitadores e inibidores. 2011. 209 f. Tese (Doutorado em Engenharia de Produção), Escola de Engenharia de São Carlos, Universidade de São Paulo, São Carlos, 2011. 
PORTER, M. E. Vantagem competitiva: criando e sustendo um desempenho superior. 32. ed. Rio de Janeiro: Campus, 1989.

POSSAMAI, A. C. Tributos federais da atividade rural: comparativo entre pessoa física e jurídica. 2017. 109 f. Monografia (MBA em Gestão do Agronegócio). Universidade Federal do Paraná, UFPR, Curitiba, 2017.

REA, L. M.; PARKER, R. A. Metodologia de pesquisa: do planejamento à execução. São Paulo: Pioneira Thomsom Learning. 2002.

SKINNER, W. Manufacturing: missing link in corporate strategy. Harvard Business Review, 47 (3), 136-145, 1969.

SLACK, N.; LEWIS, M. Operations strategy, 3rd, Pearson Education Limited, Harlow, 2011.

SOLOMON, S. A grande importância da pequena empresa: a pequena empresa nos Estados Unidos no Brasil e no mundo. Rio de Janeiro: Editorial Nórdica, 1986.

TAMARINDO, U. G. F. Tributação no Agronegócio: uma análise dos principais tributos incidentes. 2017. 260 f. Dissertação (Mestrado em Agronegócio e Desenvolvimento). Universidade Estadual Paulista "Júlio de Mesquita Filho", UNESP, Tupã, 2017.

TRIANNI, A.; CAGNO, E.; FARNÉ, S. Barriers, drivers and decision-making process for industrial energy efficiency: A broad study among manufacturing small and medium-sized enterprises. Applied Energy, v. 162, p. 1537-1551, 2016. Disponível em: < https://www.sciencedirect.com/science/article/pii/S0306261915002639>. Acesso em: 26 de jul. 2018.

VOSS, C.; TSIKRIKTSIS, N.; FROHLICH. Case research in operations management. International Journal of Operations and Production Management, 22, (2), 195-219, 2002.

WARD, P.; LEONG, G. K.; BOYER, K. K. Manufacturing proac-tiveness and performance, Decision Sciences, 25 (3), 337-358, 1996.

WELSH, J. A.; WHITE, J. F. A small business is not a big business. Harvard Business Review 59 (7), 18-32, 1981.

WHEELWRIGHT, S. C. Reflecting corporate strategy in manufacturing decisions. Business Horizons, 21 (1), 57-66, 1978.

WHEELWRIGHT, S. C. Manufacturing strategy: defining the missing link. Strategy Management Journal, 5 (1), 77-91, 1984.

ZANON, C. J.; ALVES FILHO, A. G.; JABBOUR, C. J. C.; JABBOUR, A. B. L. S. Alignment of operations strategy: exploring the marketing interface. Industrial Management \& Data Systems, 113 (2), $207-233,2013$. 